\title{
TECNOLOGIAS DA INFORMAÇÃO A SERVIÇO DA EMANCIPAÇÃO: o caso da Pesquisa sobre o Curso EaD "Dívida Pública em Debate"
}

\author{
Antonio Donizetti Sgarbi \\ Instituto Federal do Espírito Santo - IFES \\ antonio.sgarbi@ifes.edu.br \\ Leonardo Bis dos Santos \\ Instituto Federal do Espírito Santo - IFES \\ leonardo.bis@ifes.edu.br
}

\begin{abstract}
RESUMO
O artigo se propõe a discutir uma experiência que une extensão, ensino e pesquisa por meio de um curso na modalidade EaD. Enfatiza o uso das Tecnologias da Informação a serviço da emancipação dos sujeitos. Investiga o processo a partir de uma Pesquisa de intervenção social, uma variante das pesquisas qualitativas do tipo participante. Os momentos metodológicos foram: planejamento da ação de intervenção (curso) a partir de uma demanda social; desenvolvimento das ações e documentação do processo; replanejamento de cada etapa a partir da avaliação da anterior; descrição do processo e análise dos dados registrados à luz da categoria "tecnologias sociais emancipatórias". A intervenção se deu a partir de uma prática pedagógica experimental (uma espécie de laboratório de tecnologia social) que debateu a temática Dívida Pública: onde e como ela afeta a sua vida? Tal objetivo foi materializado a partir da parceria do Instituto Federal do Espírito Santo (Ifes) com o Núcleo Capixaba da Auditoria Cidadã da Dívida. Envolveu, como sujeitos da ação, lideranças comunitárias, estudantes e professores. Conclui apontando que, no caso do curso em tela, foi válida a proposta em prol de uma educação emancipadora a partir das TICs e da EaD; que existem elementos que devem ser revisados e outros reforçados numa proposta de reoferta. De forma geral, a experiência apresentou indícios de um processo de emancipação em especial pelo conteúdo (temática discutida), pela forma de trabalho (TICs e modalidade EaD a serviço da educação emancipadora) e pelo método de investigação pesquisa de intervenção social como uma ferramenta possível de ação planejada, avaliação e análise dos dados tendo sempre em vista a transformação de uma determinada realidade social.
\end{abstract}

Palavras-chave: EaD e emancipação. Pesquisa intervenção. Escola \& Movimentos Sociais. Investigações alternativas. 
INFORMATION TECHNOLOGIES AT THE SERVICE OF EMANCIPATION: the research on the online course "Public Debt in Debate"

\begin{abstract}
This article aims to discuss an experience that unites extension, teaching and research through a course in the EaD modality. It emphasizes the use of Information Technologies at the service of the emancipation of subjects. It investigates the process through a Social Intervention Research, a variant of qualitative research of the participant type. The methodological moments were: planning of the intervention action (course) based on a social demand; development of actions and documentation of the process; replanning of each stage from the evaluation of the previous one; description of the process and analysis of the data recorded in the light of the category "emancipatory social technologies". The intervention was based on an experimental pedagogical practice (a kind of social technology laboratory) that discussed the theme Public Debt: where and how does it affect your life? This objective was materialized from the partnership of the Federal Institute of Espírito Santo (Ifes) with the Capixaba Center of Citizen Debt Audit. It involved, as subjects of action, community leaders, students and teachers. It concludes by pointing out that, in the case of said course, the proposal for an emancipatory education based on ICTs and EaD was valid; that there are elements that should be reviewed and others reinforced in a re-offer proposal. In general, the experience showed indications of an emancipation process, especially by the content (theme discussed), the way of work (ICTs and the EaD modality at the service of emancipatory education) and by the investigation method of social intervention research as a possible tool for planned action, evaluation and data analysis always aiming at the transformation of a given social reality.
\end{abstract}

Keywords: EaD and emancipation. Intervention research. School \& Social Movements. Alternative investigations.

\title{
TECNOLOGÍAS DE LA INFORMACIÓN A SERVICIO DE LA EMANCIPACIÓN: el caso de la búsqueda sobre el Curso EaD "Deuda Pública en Discusión"
}

\section{RESUMEN}

El artículo tiene como objetivo discutir una experiencia que une extensión, enseñanza e investigación a través de un curso en la modalidad EaD..Destaca el uso de las Tecnologías de la Información al servicio de la emancipación de los temas. Investiga el proceso 
a partir de una Investigación de intervención social, una variante de la investigación cualitativa del tipo participante. Los momentos metodológicos fueron: planificación de la acción de intervención (curso) basada en una demanda social; desarrollo de acciones y documentación del proceso; replanificación de cada etapa de la evaluación de la anterior; descripción del proceso y análisis de los datos registrados a la luz de la categoría "tecnologías sociales emancipadoras". La intervención se basó a partir de una práctica pedagógica experimental (una especie de laboratorio de tecnología social) que discutió el tema Deuda Pública: ¿dónde y cómo afecta a su vida? Este objetivo se materializó a partir de la colaboración del Instituto Federal de Espírito Santo (Ifes) con el Centro Capixaba de la Auditoría Ciudadana de la Deuda. Implicaba, como sujetos de acción, lideranzas comunitarias, estudiantes y maestros. Concluye señalando que, en el caso del curso en pantalla, la propuesta de educación emancipadora era válida a partir de los TTE TI y de la EAD; que hay elementos que deben ser revisados y otros reforzados en una propuesta de reoferta. En general, la experiencia mostró indicios de un proceso de emancipación, especialmente por el contenido (tema discutido), la forma de trabajo (TIC y la modalidad EAD al servicio de la educación emancipadora) y el método de investigación de la investigación de intervención social como posible herramienta de acción planificada, evaluación y análisis de datos siempre con vistas a la transformación de una determinada realidad social.

Palabras clave: EAD y emancipación. Investigación de intervención. Escuela y Movimientos Sociales. Investigaciones alternativas.

\section{INTRODUÇÃO}

O objetivo deste texto é discutir o carater emancipador de uma experiência de Educação a Distância que se desenvolveu em um Curso sobre Dívida Pública no "Fórum dos Movimentos Populares, Direitos Humanos e Cidadania Emancipatória": um coletivo de Movimentos sociais e Instituições que foi registrado como Programa de extesão do Instituto Federal do Espírito Santo (Ifes). O Curso, uma parte deste Programa mais amplo, é um projeto de pesquisa e extensão que une Educação popular, não escolar, com Educação escolar na modalidade EaD. Destaca-se neste estudo o método de pesquisa intervenção desenvolvendo tecnologias sociais que une movimento social (comunidade) e escola (Instituto Federal) em vista da formação para a emancipação social.

A partir desta proposta de Pesquisa de intervenção social alguns pesquisadores do Mestrado Profissional em Ensino de Humanidades do Ifes Campus Vitória-ES - têm desenvolvido projetos de extensão e pesquisa, sendo que as temáticas das pesquisas sempre têm saído das demandas das comunidades, ou 
seja, a pesquisa é feita "com" e nunca "para" (BRANDÃO, 2006; 2017; SANTOS \& SGARBI, 2018; 2019). Foi dessa forma que nasceu o projeto da realização de um Curso na modalidade EaD, adotando uma Teoria Pedagógica Progressista, para discutir a temática "A Dívida Pública".

A pesquisa empírica em tela aconteceu, em 2019, a partir da atuação do Núcleo Capixaba da Auditoria Cidadã da Dívida [Pública] (NC-ACD), uma das 14 (quatorze) entidades que compõem o Fórum acima citado. Considerando a especificidade da proposta, o projeto contou com a parceria do Centro de Referência em Formação e Educação a Distância do Ifes (CEFOR). Assim, essa ação foi mediada pelo Programa de Extensão do Ifes. Onde o NC-ACD contribui com sua experiência de Educação Popular não escolar e o CEFOR com sua experiência de Educação a Distância (EaD).

O objetivo do Curso intitulado "Dívida Pública em debate: onde e como ela afeta a sua vida?" é, em síntese, aproximar a comunidade do debate sobre a dívida pública, buscando compreender o seu mecanismo e a importância da auditoria da dívida pública com a participação cidadã. Já o objetivo da pesquisa era fazer da experiência um laboratório de tecnologia social, onde a academia possa abrir suas portas para atender às demandas de um movimento popular.

As perguntas da pesquisa eram: como desenvolver uma educação progressista, libertadora e transformadora a partir das TICs, em um Curso de Educação a Distância (EaD) sobre Dívida Pública? Como uma pesquisa intervenção social pode auxiliar na discussão desta questão?

Para buscar resposta para tais questões o texto em tela desenvolve os seguintes tópicos: Pressupostos da ação de extensão no Ifes: Curso "A Dívida Pública em Debate" na modalidade EaD; O método: pesquisa intervenção social; Reflexões analíticas sobre a investigação realizada e Conclusões.

\section{PRESSUPOSTOS DA AÇÃO DE EXTENSÃO NO IFES: Curso “A Dívida Pública em Debate" na modalidade EaD}

\subsection{Contextos: EaD a Serviço da Extensão no Ifes}

Por que um Curso de extensão sobre Dívida Pública no Ifes? A Extensão é um dos objetivos dos Institutos Federais ao lado da Pesquisa e do Ensino. O papel dos Institutos Federais (IFs) está relacionado ao desenvolvimento local e à promoção da cidadania e neste sentido "[...] atividades de extensão tornam-se essenciais para o diálogo efetivo entre instituição e sociedade [...]". Ela é caminho "[...]de acesso dos diversos públicos às ofertas educativas e oportunidades de formação continuada, contribuindo para democratização institucional". É no diálogo com a comunidade que 
os IFs vão traçar seus objetivos de ensino de forma contextualizada e significativa, além de definir seus objetos de pesquisa de acordo com as demandas da comunidade local. "Tal postura reconhece a importância dos saberes construídos no seio dos movimentos e organizações sociais na formação do trabalhador" afirma Pacheco (2011, p. 88 - 89), um dos idealizadores da Política Pública dos IFs.

No caso concreto em tela, parte das demandas da comunidade é apresentada pelo NC-ACD cujas atividades se desenvolvem no sentido de demonstrar que com o congelamento dos gastos e investimentos sociais por 20 anos e a prorrogação, ampliação e aumento da DRU (Desvinculação das Receitas da União), os recursos destinados aos serviços públicos e às políticas sociais, em especial à educação, saúde, segurança, previdência e assistência social, que já eram insuficientes, vêm sofrendo drásticas reduções, com graves consequências para a vida das pessoas. Situação que tende a piorar ainda mais. Essas e outras medidas de ajuste fiscal foram aprovadas sem discussão com a sociedade, tendo como justificativa, a crescente dívida pública. A Constituição Federal de 1988 determinou que no prazo de 01 (um) ano fosse realizada a auditoria da dívida externa, o que não ocorreu até hoje. O que se percebe é que, quanto maiores são os gastos com pagamento de juros e amortizações da dívida pública, menores são os investimentos sociais. Discutir tais questões, envolver a comunidade na busca de seus direitos é parte da demanda apresentada pelo movimento popular (PROJETO, 2019).

O projeto de extensão aqui apresentado junta de um lado os interesses, os objetivos e as finalidades do Instituto Federal e de outro as demandas apresentadas pelo movimento social. De um lado toda estrutura acadêmica de educação formal e de outro toda uma experiência de educação popular. Disto resulta uma inovação que é colocar a EaD de uma escola pública federal à serviço da educação popular.

Além disso, a EaD, prática que veio para ficar e realidade sem volta, tem se apresentado como uma inovação frente ao ensino tradicional. Uma alternativa didática que surge como uma possibilidade de democratização do ensino, expandindo-o para os lugares onde as pessoas não têm acesso à educação presencial etc. Modalidade de ensino que vem ganhando espaço em todo o mundo e que aparece com uma resposta a muitos dos desafios que o Brasil enfrenta para garantir o acesso e a permanência dos estudantes na escola, contribui com a formação docente etc. Porém, tal modalidade não pode ser confundida com o fim da educação em si.

Desta forma, a pesquisa em tela visou discutir o uso das tecnologias de informação e comunicação como ferramenta que pode ser colocada facilmente a serviço de uma perspectiva educacional coerente com a proposta de educação que está na base daquilo que foi idealizado para dos Institutos Federais. Que perspectiva é esta? Eliezer Pacheco, um dos mentores dos Institutos Federais, ao falar da institucionalidade dos IFs e de seu projeto afirma que: 
Trata-se de um projeto progressista que entende a educação como compromisso de transformação e de enriquecimento de conhecimentos objetivos capazes de modificar a vida social e de atribuir-lhe maior sentido e alcance no conjunto da experiência humana, proposta incompatível com uma visão conservadora de sociedade. Trata-se, portanto, de uma estratégia de ação política e de transformação social. (PACHECO, 2011, p. 18).

Cientes de que as Tecnologias de Informação ou a EaD por si só não podem promover uma educação progressista manteve-se sempre o cuidado de manter a reflexão sobre os princípios educacionais dos Institutos Federais. Os pesquisadores diante dessa realidade montaram uma proposta de curso EaD com 96 horas, sendo 32 horas presenciais e 64 horas na sala de aula virtual. Relacionaram o conteúdo para ser discutido em oito módulos com atividades, textos, vídeo aulas etc., em uma sala do moodle institucional além das aulas presenciais aos sábados.

Para manter a coerência com a proposta de uma educação progressista optou-se por trabalhar com a Pedagogia Libertadora de Paulo Freire a partir da abordagem temática, cujo tema gerador/ eixo central da ação pedagógica era a Dívida Pública. Dentro dessa perspectiva as atividades pedagógicas foram desenvolvidas a partir dos três momentos pedagógicos propostos por Demétrio Delizoicov (2008): Problematização inicial, Organização do conhecimento; Aplicação do conhecimento.

Para exemplificar, expomos aqui a primeira semana do curso. A temática era riqueza e desigualdade social no Brasil. O objetivo do módulo era "analisar a realidade brasileira à luz das suas riquezas e da dívida pública". Utilizou-se como problematização inicial uma entrevista feita com a coordenadora nacional da ACD, Maria Lúcia Fattorelli. A entrevista foi conduzida pelo professor Nildo Ouriques do IELA - Instituto de Estudos Latino-Americanos da Universidade Federal de Santa Catarina. Para a organização do conhecimento utilizou-se um texto do ACD-NC (2018) denominado "Riquezas e direitos! Evolução social, avanços e retrocessos"! Para aplicação do conhecimento foi proposta a participação em um fórum de discussão, a elaboração e a apresentação de uma pesquisa, conforme enunciado da atividade: "Para você quais são as maiores riquezas do Brasil? Escolha uma delas, faça uma pesquisa sobre o tema escolhido e prepare uma apresentação sobre a mesma, postando-a no fórum da semana".

\subsection{A Experiência do Movimento Social Enriquecendo o Ifes}

$\mathrm{Na}$ parceria, o Ifes entra com toda a sua experiência e estrutura de educação formal na modalidade EaD e o NC-ACD com toda sua vivência e estrutura de educação popular. Nasceu assim o Curso no intuito de "aproximar a comunidade do debate sobre a dívida pública, com uma linguagem popular, buscando compreender os seus mecanismos e a importância da auditoria da dívida pública com a participação 
cidadã, rompendo com a visão de que o debate sobre dívida pública é apenas para especialistas da área" (PROJETO, 2019).

A base teórica do curso foi oferecida pelo Movimento Popular a partir da Cartilha "Dívida Pública - Que dívida é essa? Como ela afeta a sua vida?"-, de outubro de 2018, publicação do NC-ACD, do Instituto Genildo Batista e da Frente Estadual em Defesa da Previdência Social, dos Direitos Trabalhistas e Serviços Públicos.

A equipe de execução do projeto foi composta por quatro pessoas: dois membros do NC-ACD e dois membros do Ifes, sendo um professor e uma mestranda do Programa de Pós-Graduação em Ensino de Humanidades. A equipe se encontrava semanalmente, no início para planejar e depois para avaliar e estudar as nossas propostas.

Foi durante esses planejamentos que se optou por desenvolver um Curso, com base na Pedagogia Libertadora de Paulo Freire, na Modalidade EaD. O desejo era que o Curso pudesse servir de laboratório para estudar a possibilidade de outras experiências no mesmo estilo no qual o tripé ensino, pesquisa e extensão se tornasse realidade. No caso, a extensão nasce da demanda do movimento popular NC-ADC, o ensino se dá na modalidade EaD, com toda a preocupação de se manter uma pedagogia progressista libertadora e a pesquisa a partir do método intervenção social, o que não é muito comum.

\section{O MÉTODO: Pesquisa Intervenção Social}

\subsection{Momentos da Metodologia}

Montado o laboratório de tecnologia social o método de invesgação escolhido foi a Pesquisa intervenção social, uma variante das pesquisas qualitativas do tipo participante. $O$ desenvolvimento do processo se deu a partir dos seguintes momentos:

- acolhimento de um pedido apresentado por um movimento social, NCACD. Ou seja, o desconhecimento do processo de desenvolvimento da dívida pública e a forma como ela afeta a vida das pessoas gerou a demanda;

- resposta à demanda propondo um curso em parceria NC-ACD e Ifes, a partir da elaboração de um planejamento de intervenção social. Tal ação considerou a identidade dos sujeitos participantes (da ação de extensão e pesquisa) e a complexidade da realidade em suas múltiplas determinações (aspectos sociais, econômicos, políticos, históricos etc.);

- registro da ação de extensão em forma de curso que reúniu a infraestrutura tecnológica do Ifes com a experiência de educação popular do NC-ACD;

- desenvolvimento do curso respeitando toda política de extensão do Centro de Referência em Educação a Distância e Formação (CEFOR) do Ifes; 
- execução de contínuas reavaliações e adaptações conforme as necessidades que iam surgindo;

- documentação de todo processo para ser estudado, discutido com os participantes e pesquisadores coordenadores da pesquisa. Sempre lembrando que a ação era uma proposta de pesquisa desenvolvida numa espécie de laboratório de tecnologia social. A documentação era feita a partir da própria produção dos professores e alunos e das memórias registradas nos planejamentos e avaliações que eram feitas com pesquisadores coordenadores e com participantes;

- desenvolvimento de uma avaliação geral das atividades considerando os objetivos iniciais do planejamento e os resultados alcançados na intervenção a partir da categoria retirada das reflexões feitas no processo: "tecnologias sociais emancipatórias";

- registro dos elementos que influíram de alguma forma no desenvolvimento do processo e pudessem servir de contribuição para o desenvolvimento de novos processos. No caso cada atividade era preparada separadamente a partir da avaliação da atividade anterior e no final da atividade fez-se uma avaliação de todo o processo com os participantes que registram suas considerações em variados tipos de relato: oral, escrito ou gravado em vídeo; e

- reflexão avaliativa final retomando todo processo a partir da categoria escolhida no processo.

\subsection{Apontamentos a Respeito da Metodologia}

A escolha do método pesquisa do tipo intervenção social para auxiliar na discussão sobre as tecnologias da informação a serviço da emancipação é tão importante quanto o próprio objeto da pesquisa. Nesse sentido, um tópico para discutilo é necessário.

Sob argumentos marcadamente alinhados aos pressupostos positivistas, a pesquisa intervenção sofre críticas que pouco ou nada contribuem para seu desenvolvimento. A busca pela desqualificação dos procecimentos metodológicos, alicerçada direta ou indiretamente em preceitos quantitativos de investigação, ainda são bastantes presentes nas críticas realizadas.

A pesquisa intervenção social, contudo, pode remontar seu caminho metodológico pelo menos desde as contribuições de Marx e Engels, em que a pesquisa deixa de estar circunscrita aos seus procedimentos descritivos, ou, posteriormente, a partir do uso consciente do termo observação participante pela antropologia - quando o pesquisador se despe conscientemente da busca pela cientificidade construída até então, a partir da não interferência. As ciências sociais davam passos relevantes no sentido de superar a falsa dicotomia entre pesquisador e pesquisado. 
Nesse sentido, dando outro salto temporal e baseado nos escritos de Paulo Freire, entende-se aqui a realidade como um continuum complexo de percepções dos indivíduos na condição de pesquisador e de pesquisado numa dada situação. Essas condições se fundem na realidade empírica, uma vez que ambos fazem jus à condição de investigador do outro, alterando assim suas ações e percepções ciclicamente. Dessa forma, seguindo a obra freireana, fala-se então em elaborar pesquisas com os sujeitos pesquisados e não para os sujeitos pesquisados.

Outra consideração inicial que se faz necessária aqui dá conta de não confundir observação participante e pesquisa intervenção, apesar das similaridades em alguns aspectos. A pesquisa intervenção tem por objetivo intrínseco a obtenção de algum resultado a partir da alteração consciente da realidade, num dado contexto, observadas as condições de obtenção desse resultado. Todavia não há de se falar em resultados controlados, como aqueles realizados em biologia ou farmacologia - apesar das controvérsias -, nos quais mantidas as condicionantes se obtém o mesmo produto final. Trata-se aqui, em grandes linhas, de uma pesquisa que visa identificar uma questão-problema e encontrar soluções conjuntas com o público-alvo da pesquisa, ressaltando a dimensão da emancipação social frente aos discursos de tutela científica e política.

Teoricamente, segundo Streck, Sobottka e Eggert (2014, p. 7), o artigo "Pesquisa-ação e problema das minorias", publicado em 1946 pelo psicólogo social alemão Kurt Lewin, é um marco no debate em torno de metodologias como a aqui perseguida. A ênfase dessas pesquisas nos anos 1960 e 1970 na Europa era centrada nas relações de gênero, gerações, empregadores e empregados e na América Latina se manifestava a partir dos trabalhos desenvolvidos pelo sociólogo Orlando Fals Borda, na Colômbia e no Brasil com o educador Paulo Freire. Esta vertente desenvolveu-se a partir das práticas sociais populares na forma de teologia, pedagogia, filosofia, teatro entre outras, sempre denunciando as investidas das elites, ou do liberalismo, sobre as classes populares.

\section{REFLEXÕES ANALÍTICAS SOBRE A INVESTIGAÇÃO REALIZADA}

\subsection{Informações relevantes sobre a ação pedagógica}

Assim que o projeto do curso foi aprovadolançou-se um edital disponibilizando 30 vagas para as pessoas interessadas. Considerando que o curso começou no meio do segundo semestre houve um número pequeno de inscrições. A única exigência para se inscrever era ter concluído o ensino fundamental, mas nem todos os inscritos apresentaram a documentação correta. Segundo o edital, os candidatos deveriam ser escolhidos por sorteio, mas não foi preciso, pois a inscrição de boa parte não 
foi homologada tendo em vista a falta de documentos. Aqui encontramos o primeiro conflito entre a educação escolar e a educação popular. O interesse do Movimento Social era a educação, mas as exigências da Educação Escolar impediram que a inscrição de todos fosse homologada.

A duração prevista para o curso foi de três meses. A proposta de fazer um curso em EaD com uma temática que estava sendo mais discutida em atividades não escolares e ao mesmo tempo manter uma educação progressista libertadora motivava os proponentes.

Nas primeiras reuniões da equipe executora discutiu-se a forma como seria organizada a sala virtual e como seriam os encontros presenciais. Foi solicitado à coordenadora nacional da Auditoria Cidadã da Dívida, Sra. Maria Lúcia Fattorelli, uma saudação aos cursistas e ela atendeu prontamente. Os executores do curso gravaram também uma saudação inicial explicando a dinâmica do curso. Desde o início até o final do curso essas reuniões foram mantidas sempre no mesmo ritmo: avaliar os passos dados, planejar e executar os passos seguintes.

Analisando tal prática do ponto de vista teórico, quando relacionamos o objeto do saber ao mundo concreto, as situações reais ao saber socialmente construído estamos trabalhando com as práticas sociais que acontecem entre os seres humanos e desses com o ambiente natural. Nesse sentido, segundo Cruz, Bigliardi e Minasi (2014,p.48), temos que:

\footnotetext{
A pesquisa, vista por um olhar freriano, é uma forma de diálogo, é o diálogo entre o pesquisador e os sujeitos da pesquisa, diálogo com intencionalidades políticas, mediatizado pelo mundo e motivado pelo fenômeno de pesquisa, e a práxis - a prática social, a materialidade do mundo e a objetividade da vida - é o critério de verdade de toda a pesquisa. A práxis dos sujeitos é o critério de verdade do seu agir, porque não é no discurso que se infere o agir do sujeito, não é no discurso que ele se constitui, não está no discurso a chave de sua ontologia, mas sim no fazer humano, na práxis social, no trabalho, nas mediações com os outros homens e com a natureza.
}

Assim, a pesquisa teve que dialogar com a realidade objetiva, com o real e não com o que aparentava (que o Ifes não era uma escola inclusiva; que teríamos dificuldades para aprovar o curso etc.). Partindo do desejo dos membros do movimento social, mas sem se esquecer dos problemas enfrentados cotidianamente presentes no Instituto, inclusive o contingenciamento (corte) de verbas e a conjuntura política do país.

No decorrer do curso foi proposta, em um dos encontros presenciais, uma aula aberta já que a mesma seria ministrada pelo o professor Nildo Ouriques da Universidade Federal de Santa Catarina. O tema da aula foi: "Dívida Pública subdesenvolvimento e dependência". O professor trabalhou o tema a partir da categoria marxiana "totalidade". Ressaltou a importância de todas as lutas sociais, 
mas deixando claro que é preciso ter uma visão de conjunto da sociedade para que a transformação seja possível.

Tanto a temática acima discutida, quanto todo o conteúdo do curso provocaram não poucas situações conflituosas. Sabe-se, porém, que as mesmas fazem parte da práxis e do caminho de emancipação. As pesquisas desenvolvidas pelos pesquisadores coordenadores têm demonstrado que a emancipação social como um processo é prevista, entre outros, como a capacidade requerida para transposição das dicotomias presentes nos discursos e práticas hegemônicas. Julgamse todos estes acontecimentos como sendo de grande validade para que se perceba que mesmo trabalhando a partir de um Curso na modalidade EaD é possível propor práticas conjuntas aproveitando as oportunidades e ao mesmo tempo ir discutindo as contradições que aparecem na formação.

Frequentaram o curso até o final, dez pessoas. Entre elas conta-se um líder comunitário, um sindicalista, servidores públicos e professores. Estes juntamente com as duas pesquisadoras e os dois pesquisadores, foram os protagonistas do Curso e da pesquisa que se revelaram serem ações privilegiadas em busca da emancipação social.

\subsection{Discussão sobre a postura metodológica}

A pesquisa intervenção visa à produção coletiva de conhecimento por acreditar que o sujeito ao conhecer sua própria realidade, participa da produção de novos conhecimentos, sendo condutor desse processo.

A inserção do pesquisador, a práxis ao lado dos participantes de um Movimento Social ou de uma comunidade é o ponto inicial de uma pesquisa intervenção social. O processo começou com a aproximação dos membros do NC$A C D$, houve quem apostasse e quem não apostasse que seria possível uma ação conjunta. Ficou claro, porém no fim do processo, que a presença de um pesquisador ao lado das lideranças dos movimentos sociais pode, ao se somarem, enriquecer a todos. Assim, defende-se a postura de aproximação como sendo um elemento fundamental no processo de investigação qualitativa, o que se torna essencial em uma pesquisa intervenção. A responsabilidade do pesquisador ao propor ações concretas de alteração da realidade social, deve ser equilibrada com as possibilidades reais de realização dessas mesmas ações. Amadurecer as experiências em lidar com as expectativas dos participantes talvez seja um dos principais resultados intangíveis dessa metodologia.

Por isso, como em outras experiências que são feitas nesta mesma linha ressalta-se que a pesquisa intervenção promove a devolutiva dos dados de forma contínua. Esse aspecto é relevante no processo de promoção do amadurecimento das partes em termos de organização social. 
Tal postura visa o reforço do protagonismo comunitário. Este tem sido um dos objetivos centrais perseguidos pelos pesquisadores do Ifes, com a aproximação dos moradores dos Bairros ou dos membros dos movimentos sociais frente à Instituição de Ensino, Pesquisa e Extensão. Desse modo, alunos participantes das ações, membros dos movimentos ou moradores dos bairros são alçados à condição de falantes, expoentes de suas histórias de luta e resistência.

Esta postura tem sido um diferencial, sobretudo na proposta de pesquisas feitas nos mestrados profissionais do Ifes. Incentiva-se os(as) mestrandos(as) a realizarem pesquisas que partam das demandas dos movimentos sociais, dos grupos comunitários, ou seja, da sociedade em geral. Pesquisas que são desenvolvidas sempre "com" e não "para". Isso vai ao encontro da reflexão que fazíamos no início deste texto ressaltando a forma de fazer educação dos IFs. Relembramos que é no diálogo com a comunidade, com os movimentos sociais que os IFs vão traçar seus objetivos de ensino de forma contextualizada e significativa, além de definir seus objetos de pesquisa de acordo com as demandas da comunidade local. Essa é uma forma de reconhecer a importância dos saberes construídos no seio dos movimentos sociais e organizações sociais na formação do trabalhador.

Finalizando considera-se que esta é apenas uma primeira reflexão sobre os resultados dessa proposta de pesquisa, tendo por objetivo o desenvolvimento de tecnologias sociais de emancipação social. Fica claro que muitas outras discussões podem ser levanadas a partir da ação de intervenção em tela. Vale lembrar que tais discussões podem aprofundar a mensuração a partir da participação de um movimento social na construção e execução de uma ação coletiva. Entende-se que a participação é um indicador relevante na construção de métricas qualitativas tomando o objetivo a ser considerado.

\section{CONCLUSÕES}

A partir do texto aqui apresentado podem-se traçar algumas conclusões. A primeira delas é que o desafio de efetivar uma educação transformadora, progressista, a partir das Tecnologias da Informação, materializado aqui no Curso para discutir a Dívida Pública na modalidade EaD foi uma ocasião de novas aprendizagens. A metodologia utilizada, ou seja, a pesquisa de intervenção social, como desdobramento da pesquisa participante foi um diferencial desta ação. Tal metodologia mesmo que estranha aos padrões acadêmicos em geral, tem sido cada vez mais utilizada, sobretudo quando se tem o horizonte da pesquisa aplicada em ciências humanas - especialmente para o objetivo em tela: desenvolvimento de tecnologias sociais e da informação em vista da emancipação social. Este tipo de pesquisa requer rigor investigativo, como qualquer outra metodologia. Relevante nesse sentido é buscar 
alternativas para mensurar resultados. Outro entrave para o desenvolvimento desse tipo de pesquisa é o tempo requerido para o entrelaçamento de expectativas, entre sujeitos - pesquisados e pesquisadores, numa combinação complexa e constante.

Outra conclusão é em relação às ações desenvolvidas, seja nos círculos de cultura, seja nos fóruns realizados nas salas virtuais. As mesmas deram elementos para uma reflexão sobre a possibilidade de se utilizar a tecnologia da informação e a educação na modalidade EaD para trabalhar a emancipação humana, seja em termos de pessoas seja em termos de sociedade, por exemplo quando se está buscando a soberania do país.

Existem, porém ainda muitos pontos a serem investigados nestas ações. $O$ texto em tela se manteve basicamente na questão da possibilidade de desenvolver uma educação progressista, transformadora a partir das tecnologias da informação, em um Curso de Educação a Distância (EaD) e na metodologia da pesquisa de intervenção. E nestes pontos a pesquisa percebeu indícios que é possível sim desenvolver uma educação de caráter progressista a partir da modalidade $\mathrm{EaD}$ e que é possível o diálogo com educação popular.

Vale registrar entre as conclusões a descoberta de elementos que devem ser repensados nas próximas ofertas. Por exemplo, das 96 horas do curso, 32 horas foram presenciais. Entre os que se inscreveram no curso havia pessoas da região metropolitana de Vitória, mas também cursistas do norte e do sul do Estado. Um cursista para estar nos sábados em Vitória tinha que viajar na noite de sexta-feira, fazer o curso nos sábados pela manhã e passar o resto do dia para voltar para sua cidade. Concluiu o curso, mas com muita dificuldade. Logo, a reoferta necessariamente terá que acontecer com o mínimo de carga horária presencial. Outra questão que ficou muito clara foi à necessidade de rever a questão burocrática. Pois, quando se trabalha com lideranças populares nem sempre é viável exigir que todos tenham concluído o primeiro grau. Ainda temos muito boas lideranças que não têm "diplomas" ou certificados.

Entre os elementos que podem ser destacados, encontra-se o caráter inovador da ação que juntou a estrutura oferecida pelo Instituto Federal e a experiência de educação popular oferecida pelo NC-ACD, fundando nesta parceria um laboratório de tecnologia social cuja experiência poderá ser utilizada com inúmeros outros movimentos sociais e populares fazendo com que a comunidade esteja mais presente na escola e a escola esteja mais atenta às necessidades das organizações sociais e populares.

Deve-se ressaltar que foi de grande valia a infraestrutura do Ifes que ofereceu a tecnologia para desenvolver uma atividade na modalidade EaD, oportunizando aos próprios líderes comunitários, executores do projeto e da pesquisa o domínio de novas tecnologias. 
Enfim, pode-se dizer, de forma geral, que a experiência contribuiu para o processo de emancipação: pelo conteúdo, pois a temática do curso, dívida pública, dentro de um espírito de popularização da discussão sobre economia foi de extrema importância; pela forma, pois a escolha do trabalho, por meio das TICs e da modalidade $\mathrm{EaD}$ foi um elemento decisivo para que o curso acontecesse.

Ficou claro para os participantes da pesquisa que é preciso tomar cuidado para manter a postura de uma educação que seja dialógica, participativa. Que é preciso ensinar educando. Oferecer conteúdo substancial sempre ligado aos interesses comunitários. Daí a importância dos três momentos pedagógicos da pedagogia libertadora.

E por fim vale registrar o valor da proposta metodológica. A pesquisa de intervenção social com ferramenta possível de investigação, análise, reflexão e de transformação da realidade, a partir da formação de pesquisadores e da promoção de processos de sensibilização, efetivando uma educação de caráter progressista. A forma de investigação participante torna-se formativa, provoca uma educação problematizadora e envolvente. Nessa modalidade de pesquisa, as intervenções podem ajudar a atingir uma perspectiva de educação popular, em espaços de educação escolar, ou não, no sentido de desenvolver tecnologias sociais de mobilização e realização de ações coletivas.

Enfim, apresentam-se aqui indícios de uma experiência fundamentada em um tripé, que em sua materialidade reúne: ação de extensão realizada a partir da parceria de uma instituição acadêmica com um movimento social comprometido com o protagonismo popular e com uma nação independente; ensino na modalidade EaD, que se esforça por colocar as TICs a serviço de uma educação progressista e libertadora e na pesquisa do tipo intervenção que se desenvolve "com", avaliando e replanejando suas ações continuamente, sempre em vista do processo de formação de pesquisadores e estimulando a emancipação de pessoas e sociedades.

\section{REFERÊNCIAS}

BRANDÃO, C.R. A pesquisa participante e a participação da pesquisa. Disponível em: http://docslide.com.br/download/link/a-pesquisa-participante-e-a-participacao-dapesquisa. Acesso em: 12 fev.2017.

BRANDÃO, C. R. Pesquisa Participante. São Paulo: Brasiliense, 2006.

BRASIL. Decreto $n^{\circ}$ 5.622, de 19 de dezembro de 2005. Disponível em: https:// www2.camara.leg.br/legin/fed/decret/2005/decreto-5622-19-dezembro-2005-539654publicacaooriginal-39018-pe.html_Acesso em: 13 out. 2019. 
CRUZ, R. G.; BIGLIARDI, R. V.; MINASI, L. F. (2004). A dialética materialista de Paulo Freire como método de pesquisa em educação. Conjectura, Caxias do Sul, v. 19, n. 2, p. 40-54, maio/ago. 2014. Acesso em: 20 ago. 2017.

DELIZOICOV, D. Didática Geral. Florianópolis: UFSC/EAD/CED/CFM, 2008.

FALS BORDA, O. (1988). Aspectos teóricos da pesquisa participante: considerações sobre o significado e o papel da ciência na participação popular. In: BRANDÃO, C. R. Pesquisa participante. São Paulo: Brasiliense, 2006, p. 42-62.

FREIRE, P. (1988). Criando métodos de pesquisa alternativa: aprendendo a fazê-la melhor através da ação. In: BRANDÃO, C. R. Pesquisa participante. São Paulo: Brasiliense, 2006, pp. 34-41.

FREIRE, P. Pedagogia do Oprimido. 17. ed. Rio de Janeiro: Paz e Terra, 2001.

C-ACD; IGB; FRENTE ESTADUAL em Defesa da Previdência Social, dos Direitos Trabalhistas e Serviços Públicos. Dívida Pública - Que dívida é essa? Como ela afeta a sua vida? [Vitória: NC-ACD; IGB, 2018?].

PACHECO, Eliezer (org.). Institutos federais uma revolução na educação profissional e tecnológica. São Paulo: Santilla; Brasília: Moderna, 2011.

PROJETO DO CURSO. A Dívida Pública em Debate. Onde e como ela afeta a sua vida. Vitória: Ifes/Cefor, 2019 (mímeo).

SAVIANI, Dermeval. História das Ideias Pedagógicas no Brasil. Campinas: Autores Associados, 2010.

SANTOS, Leonardo Bis dos; SGARBI, Antonio Donizetti. Escola e comunidade: pesquisa e extensão em busca da cidadania emancipatória. Revista Brasileira de Extensão Universitária, v. 9,n. 3, set./dez. 2018, p. 135-146.

SANTOS, Leonardo Bis dos; SGARBI, Antonio Donizettti; SANTIAGO, Izabella Costa. Pesquisa intervenção e o desenvolvimento de tecnologias sociais: comunidade, escola e emancipação social". Atas do $8^{\circ}$ Congresso Ibero-Americano de intervenção qualitativa, Lisboa - Portugual. 2019. Disponível em: https:// proceedings.ciaiq.org/index.php/CIAIQ2019/article/view/2191/2116. Acesso em: 15 out. 2019.

STRECK, D. R.; SOBOTTKA, E.A.; EGGERT, E.(org.). Conhecer e transformar: Pesquisa-ação e pesquisa participante em diálogo internacional. Curitiba: CRV, 2014. 


\section{BIOGRAFIA DOS AUTORES}

ANTONIO DONIZETTI SGARBI - Possui graduação em Filosofia e doutorado em Educação: História e Filosofia da Educação pela Pontifícia Universidade Católica de São Paulo (PUC/SP - 2001). Atua como professor do Programa de Pós-Graduação em Educação em Ciências e Matemática - EDUCIMAT - do Instituto Federal do Espírito Santo - Campus Vila Velha

LEONARDO BIS DOS SANTOS - Possui graduação em Ciências Sociais e doutorado em História, na área de concentração em História Social das Relações Políticas, pela Universidade Federal do Espírito Santo (UFES - 2016). Coordenador do Programa de Pós-Graduação em Ensino de Humanidades - PPGEH - do Instituto Federal do Espírito Santo - Campus Vitória

Data de recebimento: 01/09/2020

Data de aprovação: 23/10/2020 